\title{
LA EVALUACIÓN DEL DESARROLLO NACIONAL: APROXIMACIONES A PARTIR DEL ESQUEMA DE LA PLANIFICACIÓN PRESUPUESTARIA
}

\author{
Rolando Bolaños Garita ${ }^{1}$
}

Recibido: 29/07/2014

Aceptado: 01/10/2014

\begin{abstract}
RESUMEN
La correcta ejecución de los recursos incluidos en los presupuestos públicos pasa inexorablemente por comprender primeramente el esquema planificador del desarrollo nacional, el cual debe constituirse a la luz de las dimensiones política, administrativa, jurídica y conceptual que dan sustento y forma al mismo. Bajo esas consideraciones, cualquier evaluación que se haga estaría distorsionada y no agregaría valor al mejor uso que se haga de los limitados recursos presupuestarios públicos, si no se logran comprender dichas dimensiones $y$, correlativamente, activar la serie de mecanismos y acciones de dirección gubernativa que permite la Constitución Política y la serie de normas vigentes. Por lo tanto, la consecución del desarrollo nacional podrá cristalizarse siempre y cuando los Poderes Ejecutivo y Legislativo tengan una clara noción de lo anterior y pongan a funcionar sus capacidades de dirección política y control político, respectivamente.
\end{abstract}

PALABRAS CLAVE: PLANIFICACIÓN PRESUPUESTARIA, DESARROLLO NACIONAL, DIRECCIÓN GUBERNATIVA, EVALUACIÓN POLÍTICO-ADMINISTRATIVA.

\begin{abstract}
Successful performance of public budgets inexorably forces to understand the scheme of national development planning, which should be formed by political, administrative, legal and conceptual dimensions that sustain and shape to it. Therefore, any assessment would be distorted and does not add value to public budget resources, if it does not understand these dimensions first, and activate the series of mechanisms and actions of governmental direction established in the Constitution and other laws. Then, the achievement of national development may crystallize as long as the executive and legislative branches have a clear notion of this scheme, and put their skills to work around or over the key factors of policy direction and political control, respectively.
\end{abstract}

KEY WORDS: BUDGET PLANNING, NATIONAL DEVELOPMENT, GOBERNMENTAL DIRECTION, POLITICAL AND ADMINISTRATIVE ASSESSMENT.

1 Universidad Estatal a Distancia, Escuela de Ciencias de la Administración, Código Postal 29-2020, Costa Rica. rbolanos@uned.ac.cr 


\section{INTRODUCCIÓN}

El presente artículo resume la investigación llevada a cabo sobre la planificación presupuestaria en la administración pública costarricense y su implicancia en el desarrollo nacional. La motivación para ello es precisamente generar un aporte tangible al mejor accionar gubernativo, el cual debe estar totalmente focalizado hacia la satisfacción de las necesidades poblacionales $y$ a las oportunidades del desarrollo, sea en el campo educativo, de salud, seguridad ciudadana, desarrollo agroalimentario, infraestructura nacional, etc.

Se pretende de esta manera, fortalecer ese espíritu siempre latente de auscultación sobre la res publica, añadiéndole datos actualizados sobre el desempeño presupuestario, los cuales se espera que sean de utilidad para potenciar la reflexión sobre el curso de acción que están tomando dichos recursos para materializar el desarrollo nacional.

\section{MARCO TEÓRICO}

\section{Definición de la temática investigada}

Debido a que el Gobierno costarricense detenta una responsabilidad ineludible para el mejoramiento en la calidad de vida de los ciudadanos y habitantes del país; que la materialización de las actividades y objetivos institucionales, así como los planes y proyectos de carácter nacional/global son los que en definitiva permiten la concreción de tal responsabilidad; $y$ que estos son posibles en razón de los recursos presupuestarios con que cuentan las instituciones públicas, resulta necesario realizar un análisis más detallado sobre la serie de estrategias, directrices y acciones que desde las Ciencias de la Administración ${ }^{2}$ está desplegando el Poder

2 Para aclarar este concepto nos basamos en Henry Fayol, quien se refiere así a las Ciencias Administrativas:

El significado por mí atribuido al término administración, y generalmente adoptado, amplía en forma notable el dominio de las ciencias administrativas. Además de los Servicios Públicos, él comprende también a las empresas de cualquier índole,
Ejecutivo en materia de dirección, planificación, organización, control y evaluación de su gestión ${ }^{3}$, especialmente a través de una sana y transparente ejecución de los recursos públicos por él administrados.

Es importante reiterar que son esos recursos los que, según principios de eficiencia y eficacia, logran una gestión institucional de comprobado apego al cumplimiento del Plan

amplitud, forma y objeto. Todas las empresas necesitan previsión, organización, mando, coordinación y control; para funcionar debidamente, todas han de respetar los mismos principios generales. Ya no se trata de varias ciencias administrativas, sino de una sola ciencia que se aplica tanto en los asuntos públicos como en los privados, $y$ ambos elementos principales se encuentran, resumidos, en lo que hoy se denomina doctrina administrativa. (Fayol, 1957, p.179-180)

Empero, quisiéramos abonar a lo prescrito por Fayol, acotando que nuestra formación y experiencia académico-laboral nos sustenta para advertir que la realidad político-jurídica que rige a la administración pública, difiere diametralmente de la realidad jurídico-lucrativa que rodea a las empresas privadas. La primera se constituye en todo un sistema político-administrativo que ve su razón de ser en las necesidades de la sociedad a la que pertenece y por tanto sus instituciones se modelan a partir del cumplimiento de sus objetivos sociales, sin que sea el lucro o la ganancia la razón primordial (para un mejor detalle sobre esta disparidad entre gestión administrativa pública y gestión administrativa privada, consúltese Introducción al análisis de la Burocracia Pública, de Johnny Meoño Segura, Eucr, San José, 1980). De igual forma, el principio de legalidad al que se ve sujeta la primera, no lo notamos en lo más mínimo en la administración privada.

$3 \quad$ El orden presentado aquí del denominado Proceso Administrativo, inicia con el Principio de Dirección, al concordar plenamente con Meoño Segura (1986), quien visualiza ese orden lógico, al presentar la Dirección como una función y una fase que da inicio y dinámica a la plena realización del proceso en mención. Nuestra concordancia es total, ya que dicho detalle argumentativo vislumbra que el respectivo jerarca echará mano a su capacidad de dirección, o sea, a su autoridad, para dinamizar lo correspondiente a las otras fases procesales. Esto no podría ser de otra forma, ya que sin autoridad, el resto de fases no serían dables, al carecer de legitimación. 
Nacional de Desarrollo (PND).Al hablar de eficiencia $y$ eficacia como filtros para mejor valoración de programas y acciones públicas que esquematizan un PND como herramienta para el desarrollo integral del país, debemos referirnos a la concepción que sobre estos brinda el autor costarricense Johnny Meoño Segura, en su obra Introducción al análisis de la burocracia pública (1980). En ella, el autor aclara que la eficiencia y la eficacia pública no pueden ser medidas en términos idénticos a la gestión privada. Por ejemplo, un programa de ayuda social como comedores escolares, becas estudiantiles o una calle cantonal, podrán no ser eficaces en términos de resarcimiento de costos; incluso, podrían considerarse un gasto irrecuperable para el Gobierno; no obstante, en términos de la responsabilidad social del Estado como salvaguarda de las clases sociales vulnerables y de los derechos de los habitantes de la República, dichas acciones le son irrenunciables; lo cual no significa que deban darse sin controles, y por el contrario incurrir en el despilfarro. Así, a pesar de su irrecuperabilidad económica directa, por decirlo de algún modo comprensible, los programas antes mencionados no son eficientes, pero sí eficaces cuando llegan a la población indicada.

En este sentido, el PND es el instrumento articulador por excelencia con que cuenta el Poder Ejecutivo para lograr un desarrollo nacional coherente y sostenido, donde todos los recursos humanos, técnicos y financieros públicos deben dedicarse a su fiel cumplimiento, $y$ al tomar en cuenta que la gestión presupuestaria se incluye dentro de esta dedicación irrestricta, se pretende lograr un análisis integral de los esfuerzos públicos traducidos en acciones administrativas para cumplir con lo anterior. Se busca analizar el espectro que rodea a las instituciones públicas y su aporte al desarrollo nacional a partir de la Ley de Administración Financiera de la República y Presupuestos Públicos 8131, a través de la cual los Ministerios de Hacienda y Planificación Nacional, y en gran parte la Contraloría General de la República, juegan un papel decisivo en esa materialización del desarrollo.

Así, resulta necesario valorar la serie de instrumentos administrativo-financieros emitidos por los entes antes señalados, los cuales deberían ser piedra angular para la consolidación del PND, a través del enlace de esfuerzos de los entes públicos sometidos a la dirección gubernativa del Poder Ejecutivo. Lo anterior toma mayor fundamento cuando incluso el Programa de las Naciones Unidas para el Desarrollo (PNUD) y el mismo Ministerio de Planificación Nacional (MIDEPLAN), desarrollaron el proyecto Fortalecimiento de la planificación (planeación, presupuestación y evaluación) estratégica del Estado costarricense (Proyecto 00074538), el cual ha impulsado consultorías para determinar las acciones tendentes al mejoramiento de la gestión administrativa pública en razón del PND y el mejor cumplimiento de las responsabilidades de ese Ministerio en materia de la Ley de Planificación Nacional 5525, así como de la necesaria inter-coordinación con otras instituciones públicas pertenecientes al Sistema Nacional de Planificación, instituido en esa norma jurídica.

Sumado al proyecto anteriormente citado, también el Banco Interamericano de Desarrollo (BID) proveyó de financiamiento a MIDEPLAN para concretar la consultoría Desarrollo y fortalecimiento del Sistema Nacional de Inversiones Públicas (Proyecto CR-T1008), el cual prácticamente replica lo ya generado a través del PNUD.

Finalmente, MIDEPLAN también ha pasado a formar parte del proyecto Fomento de las Capacidades de Evaluación en Centroamérica (FOCEVAL), impulsado por el Ministerio Alemán de Cooperación Económica y Desarro1lo. El objetivo principal del mismo resulta en el fortalecimiento de la evaluación para la toma de decisiones y la conducción política.

Las consultorías y proyectos referidos, evidencian la necesidad de valorar la serie de instrumentos que desde las Ciencias de la Administración consolidan y potencian el Sistema de Planificación Nacional. Dicho sistema, que debería estar encauzado en el cumplimiento de la Ley 5525 y del Plan Nacional de Desarrollo, no se puede concebir desligado de la Ley de Administración Financiera de la República y Presupuestos Públicos 8131 (LAFRPP), de la Ley para el equilibrio financiero para el Sector Público 6955, de la Ley General de la Administración 
Pública 6227 (LGAP), y, si se quiere, de la Ley de Contratación Administrativa 7494 (LCA), las cuales cierran un círculo jurídico-técnico de gran valía para el mejor desempeño de todos los recursos administrados por el Gobierno costarricense.

Precisamente, ubicamos la forma en que se cierra dicho círculo, en parte al valorar los trabajos académico-científicos de Meoño Segura (2005, 2008, 2011a, 2011b y 2012), al concebir el presupuesto público como un instrumento del Poder Ejecutivo para dirigir presupuestariamente a las instituciones públicas cubiertas bajo su alero y vincularlas al PND, lo cual es posible mediante el abordaje conexivo de la planificación nacional mediante la ley 5525 , la dirección gubernativa explicitada en la ley 6227 y la correspondiente emisión de directrices, así como en la presupuestación pública, con base en la ley 8131.

En esa misma línea, pero desde nuestro criterio analítico, a las anteriores deben sumárseles la esquematización presupuestaria y su vinculación al PND, en los términos prescritos en el artículo 4 y siguientes de la ley 6955; y finalmente, la sujeción de cualquier compra pública de bienes o servicios al PND, con fundamento en la contratación administrativa pública dictada en la ley 7494 .

Notará entonces el lector que, todos los recursos presupuestarios públicos tienen al PND como eje gravitacional, como articulador $y$ contralor por excelencia. La planificación nacional en todos sus extremos, desde la activación de acciones programáticas, la esquematización presupuestaria, $y$ ahora también la adquisición de bienes y servicios por las instituciones públicas, no deben escapar a la vinculación con la carta de navegación por excelencia para alcanzar el desarrollo nacional en todos sus campos, o sea, el PND.

En otras palabras, nos encontramos frente a un problema atinente a la aplicabilidad de las Ciencias de la Administración en varias de sus dimensiones, específicamente en lo tocante al proceso administrativo: dirección, planificación, organización, control y evaluación, y la manera en que se desarrollan estrategias e instrumentos para su cumplimiento; pero sobre todo de la forma en que la Administración Pública concreta la toma de decisiones gubernativo-gerenciales con base en dichas ciencias.

Y es que, la dinámica institucional planificación-presupuesto debe atender el bloque de legalidad dispuesto, el cual debe ser un marco orientador de claridad plena, capaz de reflejar elementos teórico-conceptuales de reconocida valía para el mejor desempeño de la Administración Pública, desempeño que podría deslindarse en el tanto no contenga adecuadas pautas para un sólido alineamiento de los recursos presupuestarios para con las políticas gubernativas, mismas que se sustentan en las metas $y$ tipos de medios prescritos en la Ley General de la Administración Pública y defendidos a ultranza por Meoño Segura en sus publicaciones. Son estos últimos: metas y tipos de medios, parte del argot administrativo público que consideramos no han sido finalmente comprendidos por los administradores públicos (planificadores, responsables presupuestarios $y$ jerarcas de turno), en razón de la impecable importancia que tienen los mismos para la conducción de la constelación de instancias públicas, la cual se evidencia a partir de la obligación de las mismas por lograr su cuota en el PND.

Para mejor ilustración de lo supraindica$\mathrm{do}^{4}$, valórese la capacidad de dirección gubernativa que ostentan el Presidente de la República y sus Ministros a través de la LGAP, en los siguientes artículos de la LGAP:

Artículo 26.-El Presidente de la República ejercerá en forma exclusiva las siguientes atribuciones:

...b) Dirigir y coordinar las tareas de Gobierno y de la Administración Pública central en su total conjunto, $y$ hacer lo propio con la Administración Pública descentralizada;

c) Dirimir en vía administrativa los conflictos entre los entes descentralizados $y$

$4 \quad$ En esa misma línea, puede consultarse también el artículo del autor (2012), en el cual se detalla lo relativo a los fundamentos históricos de la LGAP y la capacidad de dirección gubernativa. 
entre éstos y la Administración Central del Estado;

Artículo 27.-

Corresponderá a los ministros conjuntamente con el Presidente de la República las atribuciones que les señala la Constitución $y$ las leyes, $y$ dirigir y coordinar la Administración, tanto central como, en su caso, descentralizado, del respectivo ramo.

Artículo 98.-

El Poder Ejecutivo, dentro del ramo correspondiente, podrá remover y sustituir, sin responsabilidad para el Estado, al inferior no jerárquico, individual o colegiado, del Estado o de cualquier otro ente descentralizado, que desobedezca reiteradamente las directrices que aquel le haya impartido sin dar explicación satisfactoria al respecto, pese a las intimaciones recibidas. Cuando se trate de directores de instituciones autónomas la remoción deberá hacerla el Consejo de Gobierno.

Artículo 99.-

1. Habrá relación de dirección cuando dos órganos de administración activa tengan diversa competencia por razón de la materia y uno de ellos pueda ordenar la actividad, pero no los actos, del otro, imponiéndole las metas de la misma y los tipos de medios que habrá de emplear para realizarlas, dentro de una relación de confianza incompatible con órdenes, instrucciones o circulares.

Artículo 100.-

1. Cuando un órgano tenga potestad de dirección sobre otro podrá impartirle directrices, vigilar su cumplimiento y sancionar con la remoción al titular que falte a las mismas en forma reiterada y grave, sin justificar su inobservancia.

2. El órgano director no tendrá como tal potestad jerárquica sobre el dirigido, $\underline{y}$ éste tendrá en todo caso discrecionalidad para aplicar las directrices de acuerdo con las circunstancias.

Se extrae del articulado anterior, que el mecanismo jurídico con que cuenta el Poder Ejecutivo para someter a la administración central $y$ descentralizada a lo establecido en el PND, es mediante la emisión de directrices, las cuales establecerán las metas del desarrollo y los tipos de medios para lograr las mismas. Según criterio del autor de este ensayo, las metas son los proyectos públicos de orden nacional enunciados en el PND, y los tipos de medios serían los presupuestos públicos, o sea, los recursos económicos que posibilitarán tales proyectos.

La falta de entendimiento conceptual y operativo de los términos ya indicados, así como de otros inherentes a la Administración Pública costarricense, impacta sensible y negativamente en la forma en que se determinan los resultados que se espera alcanzar al término del ejercicio presupuestario, al igual que en las acciones, los medios y recursos necesarios para obtenerlos. Lo anterior abona al desempeño errado y desintegrado del aparato estatal, en el cual conceptos de sector de actividad administrativa y región de desarrollo deberían estar implícitos en la planificación presupuestaria. Tampoco se incluyen estos de forma adecuada en los mecanismos para la definición de la estructura programática y presupuestaria emanados por el Ministerio de Hacienda de manera unilateral o mancomunada con MIDEPLAN ${ }^{5}$, refiriéndonos con esto a:

\footnotetext{
$5 \quad$ El primero de estos instrumentos se emite vía circular por parte de la Comisión de Coordinación de la Administración Financiera, creada por el Decreto Ejecutivo 34534-H; el último se comunica por parte de MIDEPLAN a las instancias según su esfera de participación en el PND. El resto de instrumentos mencionados se emite vía Decreto Ejecutivo, en los cuales tiene gran participación la Secretaría Técnica de la Autoridad Presupuestaria y la Dirección General de Presupuesto Nacional. Sin embargo, en ellos se echa mucho de menos, tal $y$ como se indica previamente, la presencia de los términos metas $y$ tipos de medios.
} 
i. Las directrices técnicas-metodológicas para la formulación presupuestaria.

ii. Las directrices generales de política presupuestaria para las entidades públicas, ministerios, y demás órganos según corresponda, cubiertos por el ámbito de la autoridad presupuestaria.

iii. Los procedimientos para la aplicación y seguimiento de la política presupuestaria de las entidades públicas, ministerios, $y$ demás órganos.

iv. Los procedimientos para la aplicación de las directrices $y$ regulaciones generales de política salarial, empleo y clasificación de puestos para las entidades públicas, ministerios, y demás órganos según corresponda, cubiertos por el ámbito de la autoridad presupuestaria.

$v$. Las directrices y regulaciones generales de política salarial, empleo y clasificación de puestos para las entidades públicas, ministerios, y demás órganos según corresponda cubiertos por el ámbito de la autoridad presupuestaria.

vi. Los lineamientos técnicos y metodológicos para la programación, seguimiento y evaluación estratégica de sectores e instituciones del sector público.

\section{b) Antecentes de la planificación presupuestaria}

La capacidad de gestión de la administración pública costarricense se encuentra indefectiblemente relacionada con los recursos económicos y presupuestarios con que se cuenta. Esta máxima tiene su principal asidero en lo establecido en el párrafo primero del artículo 180 de la Constitución Política que señala:

El presupuesto ordinario y los extraordinarios constituyen el límite de acción de los Poderes Públicos para el uso y disposición de los recursos del Estado....

A partir de dicho artículo se requiere todo un esfuerzo articulado y coherente de acción estatal, mediante el cual se logren visualizar no solo las acciones estratégicas que permitirán la concreción de las necesidades del país, sino también la serie de instrumentos y acciones de dirección, planificación, organización, control y evaluación, que serán los canales de acción específicos para el cumplimiento de tales necesidades.

En razón de lo anterior, podemos visualizar en el panorama político-administrativo costarricense, una gama de normas (leyes, reglamentos, lineamientos técnicos, etc.) dirigidas a lograr la acción cohesionada y articulada de las instituciones administrativas públicas en pos del desarrollo nacional, lo cual debería realizarse en total apego al esquema teórico-técnico provisto por las ciencias administrativas.

Así, tenemos en primera instancia la Ley de Administración Financiera de la República y Presupuestos Públicos 8131, la cual ha entronizado todo un sistema de acción administrativofinanciero que permite encauzar, claramente, no solo la gestión presupuestaria de las instancias públicas, sino también la rendición de cuentas e incluso la aplicación de sanciones administrativas a funcionarios públicos en razón del incumplimiento al $\mathrm{PND}$, mismo que concebimos como el instrumento técnico-político por excelencia que permite al Presidente de la República guiar el accionar gubernamental bajo un enfoque sistémico.

De igual forma, se cuenta, dentro del andamiaje jurídico-administrativo, con la Ley de Planificación Nacional 5525, que desde su promulgación en 1974 sentó las bases para la planificación administrativa pública, de forma tal que las instituciones pertenecientes a la Administración Central estuvieran siempre sometidas a las directrices que emita el Presidente en materia de planificación nacional. En el caso de las instituciones autónomas, estas se encuentran sujetas a las directrices de carácter general dictadas por dicho Poder igualmente en materia de planificación nacional, así reconocido incluso por la Sala Constitucional mediante diversas Resoluciones (3309-94, 6345-97 y 200212019). Lo anterior no podría ser de otra forma, ya que en su defecto se podría incurrir en un accionar disperso y desarticulado de las mismas, $y$ en un desapego evidente e 
injustificado de las metas trazadas para un desarrollo nacional palpable y sostenido.

Al lograr enlazar la Ley 8131 y la Ley 5525 , se despliega todo un mega sistema de planificación, ejecución, control y evaluación económico-presupuestario a nivel de casi todo el aparato estatal, exceptuando a las municipalidades, Caja Costarricense del Seguro Social $y$ a las universidades estatales, ya que a estas solamente les aplican los principios establecidos en la primera de dichas normas, así como el régimen de responsabilidades estipulado $y$, finalmente, les obliga a proporcionar la información que requiera el Ministerio de Hacienda para sus estudios.

La ley para el equilibrio financiero establece una serie de pautas en materia presupuestaria y de ligamen plan-presupuesto, así como de estructura programática y de reordenamiento hacendario que deben indefectiblemente enlazarse con las dos anteriores.

Concatenado con lo anterior, debe rescatarse la Ley General de la Administración Pública 6227, la cual ha constituido un instrumento jurídico de gran valía para cerrar el círculo de acción estatal presupuestaria unificada, según la capacidad del Poder Ejecutivo de dirigir la acción estatal a través de directrices, pudiendo establecer a las instituciones de la administración central y descentralizada, las metas $y$ tipos de medios que en materia de presupuestos públicos permitan la consecución del desarrollo nacional; nuevamente, con base en el Plan Nacional de Desarrollo, verbigracia, tómense en cuenta nuevamente los artículos 26, 27, 98, 99 y 100 de aquella norma.

No deja de ser necesario señalar otras de las leyes relacionadas con la administración de los recursos económicos estatales como la Ley de Contratación Administrativa 7494, la cual igualmente somete la adquisición de bienes $y$ servicios por parte de todos los poderes de la República, universidades estatales, Tribunal Supremo de Elecciones, municipalidades e instituciones autónomas a lo establecido en el Plan Nacional de Desarrollo, cuando sea aplicable.

Como podrá notarse hasta este punto, la serie de normas indicadas brindan una plataforma de acción que pareciera a todas luces unificada dando potestades al Poder Ejecutivo (Presidente de la República y los ministros que correspondan), para encauzar la serie de planes, programas y proyectos implementados por las instituciones públicas, en aquellos campos que resulten indispensables para consolidar el desarrollo nacional, por ejemplo, en el ámbito social, económico, agrícola, educativo, de infraestructura vial, aérea o portuaria, de derechos humanos, etc. Todo lo anterior a través de una administración presupuestaria articulada y transparente, pero, sobre todo, cohesionada con el Plan Nacional de Desarrollo, tal y como ha sido expuesto supra.

No obstante lo anterior, también se logra visualizar que a pesar de que al Poder Ejecutivo se le ha brindado o dispuesto de todo un arsenal jurídico, el cual le permite establecer instrumentos técnico-administrativos (decretos, acuerdos, directrices, lineamientos, circulares, etc.) que permitan consolidar una gestión administrativo-presupuestaria articulada y encauzada al logro de la mejor calidad de vida de los habitantes del país, aún pareciera que las instituciones cubiertas bajo el alero de las leyes de marras no logran operacionalizar adecuadamente un esquema administrativo que logre un comprobado apego al mejor desarrollo nacional. Aunado a lo anterior, aún se cuenta con preceptos que pudieran considerarse segregados, refiriéndonos a los programas presupuestarios adscritos a los ministerios de Gobierno, los cuales constituyen estructuras cuasi-independientes dentro de un conglomerado mayor, que en gran cantidad de ocasiones funcionan en forma desperdigada, ajena a los parámetros de acción que pudiera dictar el Presidente de la República y el ministro respectivo.

Bajo ese prisma no queda claro el esquema articulador empleado por el Poder Ejecutivo para cohesionar tanto a los entes ministeriales en todo su espectro (incluidos Programas Presupuestarios), como a las instituciones descentralizadas del respectivo sector. Valga acotar que parece diluirse la mejor orquestación de los planes, programas, proyectos y recursos públicos a nivel de sectores de actividad administrativa por los cuales los Ministros pueden ( $y$ deben), en calidad de rectores de sector, plasmar acciones 
de dirección gubernativa más acordes con el contexto del sector respectivo.

La noción de rector de sector se ubica en dos frentes. El primero es teórico-conceptual y muy propia de Meoño, por lo que el lector interesado puede acceder a sus obras referenciadas en la bibliografía para no incurrir aquí en una distorsión conceptuosa o interpretativa. El otro frente es el normativo, ya que el primer Reglamento Orgánico del Poder Ejecutivo, Decreto Ejecutivo 34582-PLAN, lo sumaba por primera vez al arsenal técnico-jurídico criollo. Por su parte, el actual Reglamento Orgánico del Poder Ejecutivo (38536-PLAN) también lo incluye, específicamente en los artículos 4 y 5, que en lo que nos interesa señalan lo siguiente:

Artículo $4^{\circ}$-Rectorías. Entiéndase por rectoría la potestad que tiene el Presidente de la República conjuntamente con la o el ministro del ramo para coordinar, articular y conducir las actividades de cada sector y asegurarse que éstas sean cumplidas conforme a las orientaciones del Plan Nacional de Desarrollo.

Para lograr esto, el Poder Ejecutivo deberá coordinar, dar seguimiento y evaluar los resultados de las diferentes actividades que realicen las instituciones de cada sector para ejecutar las politicas públicas sectoriales, regionales e institucionales. En determinadas materias de especial interés para el Estado, la rectoría del Poder Ejecutivo, como forma de acción estatal, puede extenderse al ámbito privado de conformidad con la ley.

Artículo $5^{\circ}$-Las y los Ministros Rectores. El Presidente de la República delega en una o un Ministro con cartera, la rectoría de cada uno de los sectores. Corresponderá a las o los Ministros Rectores dirigir y coordinar la realización de las actividades sectoriales...

Artículo $6^{\circ}$-Responsabilidades de las y los Ministros Rectores. Corresponderá a la autoridad ministerial a la que el Presidente asigne la rectoría de sector, atender las siguientes responsabilidades:

a) Dirigir y coordinar al respectivo sector. b) Presentar ante el Consejo Nacional Sectorial el Plan Nacional Sectorial, las politicas, planes, programas, proyectos y estudios relacionados con el respectivo sector para su análisis y toma de decisiones colegiadas.

c) Avalar las politicas y los planes de mediano y largo plazo de las instituciones del sector, velando por su vinculación con el respectivo Plan Nacional Sectorial (PNS).

d) Visar los proyectos de inversión de las instituciones del sector para su inscripción en el Banco de Proyectos de Inversión Pública (BPIP) del Ministerio de Planificación Nacional y Política Económica.

e) Velar por la vinculación de los Planes Operativos Institucionales (POI) y de los presupuestos de las instituciones del respectivo sector con el Plan Nacional de Desarrollo $y$ con los respectivos Planes Nacionales Sectoriales.

f) Establecer e impulsar la coordinación interinstitucional y sectorial a nivel regional y asegurar la promoción y articulación de la participación ciudadana en las diversas acciones que los sectores desarrollen en estos niveles territoriales.

g) Promover la efectividad de la gestión de las instituciones del sector y su rendición de cuentas.

h) Fortalecer los procesos institucionales de formulación, seguimiento $y$ evaluación de los proyectos de inversión pública requeridos por el sector.

i) ncluir dentro del informe anual de labores prescrito en el artículo 144 de la Constitución Política, un aparte sobre los resultados del sector $y$ de su gestión de rectoría.

j) Integrar de manera participativa las opiniones de grupos de interés en los asuntos de relevancia sectorial.

k) Realizar cualquier otra actividad congruente con las funciones de rectoría sectorial. 
Tampoco se vislumbran aún instrumentos de dirección gubernativa para orquestar las mejores estrategias de acción administrativa pública que permitan formular, ejecutar, controlar y evaluar logros sostenidos a nivel de regiones de desarrollo, donde se particularicen las necesidades de aquellas comunidades que aglutina cada región, las cuales por razones de contexto socio-demográfico, económico, agroalimentario u otro, pueden diferir diametralmente entre cada una de ellas y es obligación de cada institución pública realizar todos los esfuerzos posibles según su rango de acción para solventar tales necesidades. Todo lo anterior, además de lo dispuesto en las normas referenciadas en líneas precedentes.

Lo anterior lo afirmamos, ya que la punta de lanza del abordaje planificador nacional a nivel regional lo fue el Decreto Ejecutivo 15227-PLAN "Constitución del Subsistema de dirección y planificación regional", modificado posteriormente por los decretos 18059-PLAN y 20432-PLAN, siendo este último derogado durante la administración Arias Sánchez por el decreto 33273-PLAN. Actualmente, no se localizan cuerpos normativos semejantes, que gocen de igual grado de riqueza conceptual o capacidad de orquestación burocrático-institucional. Si bien el actual Reglamento Orgánico del Sector Público rescata las nociones tanto del decreto 15227-PLAN, como del decreto 14184-PLAN "Creación del Subsistema de dirección y planificación regional", sobre las coordinaciones sectorial y regional, es aún aventurado $y$ prematuro referirse a sus posibles implicaciones para el mejor funcionamiento de la planificación presupuestaria.

En cuanto a la Contraloría General de la República, las primeras normas técnicas que en materia presupuestaria se dictaron como instrumento orientador, tuvieron una larga vida: desde 1988 hasta el 2012, por lo cual podría inferirse que durante varios ejercicios económicos, los recursos incluidos en los presupuestos públicos no respondieron necesariamente al contexto de la Administración Pública ni a sus planes, programas y proyectos del momento; $y$ en forma más específica, a los planteamientos de la Ley 8131.
En ese mismo orden de ideas, los "Lineamientos y directrices técnicas metodológicas de formulación y gestión presupuestaria" dictados por el Ministerio de Hacienda, así como los "Lineamientos técnicos y metodológicos para la programación, seguimiento y evaluación estratégica de sectores e instituciones del sector público en Costa Rica" dictados por el Ministerio de Planificación, deben analizarse con minuciosidad, buscando determinar el impacto de los mismos en la mejor gestión presupuestaria pública. Esto, ya que como se indicó en líneas precedentes, tales instrumentos técnicos no guían a los jerarcas de turno o a los técnicos de las instituciones públicas, menos aún a los Ministros Rectores de sector, sobre los mecanismos precisos para una adecuada articulación de lo sectorial y lo regional a nivel programático o presupuestario. En otras palabras, no aclaran cómo cada sector de actividad administrativa aborda $y$ solventa las necesidades poblacionales de las regiones de desarrollo por medio de los presupuestos públicos, y su necesaria vinculación con el PND.

En la actualidad, se logra denotar a través del trabajo que concretan los medios de comunicación, cómo las finanzas públicas no solo resultan blanco de críticas por su uso irracional $y$ poco articulado, sino que ahora también vienen a sumarse los déficits financieros que han presentado instituciones consideradas como emblemáticas para la sociedad costarricense, tales como la Caja Costarricense del Seguro Social (CCSS) y el Instituto Costarricense de Electricidad (ICE).

A dichos antecedentes referenciales debe sumársele el gasto realizado por el Consejo Nacional de Vialidad (CONAVI) durante el 2012, al desarrollar la construcción de la llamada Ruta Nacional "Juan Rafael Mora Porras", la cual ha sido cuestionada por muchos de los sectores nacionales debido a la carencia de planes y controles, vislumbrándose entonces un accionar financiero y presupuestario público que no encuentra un direccionamiento coherente y una planificación capaz de apuntalar hacia proyectos de interés nacional que sí logren un impacto positivo a nivel de derechos de los habitantes $y$ de necesidades poblacionales. 
Se yuxtapone a lo anterior los esfuerzos continuos por solventar el déficit fiscal y la disminución de la deuda pública interna y externa, obviando que ambos son síntomas de un mismo elemento causal: el exacerbado gasto público en que se ha incurrido a lo largo de varios periodos presidenciales, el cual se ha destacado por darse sin mayores reparos de dirección, unicidad, articulación y sinergia, incurriendo así en la incorporación de los limitados recursos económicos en presupuestos que no han sido sujeto de análisis y valoración según las condiciones socioeconómicas que lo ameritan, pero por regiones y sectores a partir del PND.

Desde 1974, cuando se emite la Ley de Planificación Nacional, pasando por el 2001, año de la promulgación la Ley de Administración Financiera de la República y Presupuestos Públicos, y hasta el año en curso, se han venido formulando, discutiendo, aprobando, ejecutando, fiscalizando y liquidando presupuestos públicos y estructuras programáticas que debían responder a necesidades poblacionales correctamente interpretadas $y$ detectadas mediante el despliegue de esfuerzos y recursos con que debe contar el Sistema Nacional de Planificación, lo cual no ha ocurrido, al considerar que falta aún una serie de consideraciones legales, conceptuales y metodológicas que logren un presupuesto de la República debidamente aprobado por la Asamblea Legislativa que no dé asomos de distancia entre este y el PND.

El mejor uso de los recursos públicos incluidos en presupuestos institucionales tiene finalmente, una sola razón de ser, indicada previamente: la atención de derechos de los habitantes y la concreción efectiva de las necesidades poblacionales. Pero esto es posible de llevar a cabo, nuevamente recurriendo a los planteamientos de Meoño Segura, primero si se tiene claridad de los preceptos constitucionales de primer orden, como por ejemplo el artículo 50 de la Constitución Política y, en segundo lugar, la otra serie de preceptos localizados en las leyes orgánicas y leyes especiales que explicitan las actividades de los entes públicos. Tales preceptos constituyen un Modelo-País que otras fuerzas y sectores nacionales viven implorando a los cuadros políticos en ejercicio, o bien, a aquellos próximos a competir en la contienda electoral que nuestro sistema político tiene cada cuatro años.

La desatención al modelo sustenta la erraticidad en el accionar gubernamental, tanto en lo estratégico y operativo, como en lo presupuestario a nivel de planificación, ejecución, control y evaluación de los recursos financieros dispuestos y aprobados por la Asamblea Legislativa y por la Contraloría General de la República, instancias que no parecen aplicar valoraciones más rigurosas que enderecen el desempeño estatal y propulsen la mejor administración de la Hacienda Pública.

Con base en todo lo anterior, se vislumbra que la falta de conocimiento o claridad por parte de cuadros gubernativos y técnico-administrativos de esas consideraciones en materia de planificación presupuestaria, es antecedente suficiente para generar un abordaje académicoinvestigativo al respecto, lo que busca esclarecer también el detalle operativo que rodea la formulación, evaluación y fiscalización de los presupuestos de la República.

\section{c) El objetivo general de la investigación}

Elaborar un diagnóstico que permita identificar la vinculación de la planificación presupuestaria al Plan Nacional de Desarrollo por parte de las instituciones públicas.

\section{RESULTADOS}

La forma más coherente y tangible para determinar el vínculo entre la planificación presupuestaria y los respectivos PND, se ubica a partir los niveles totales y porcentuales de recursos incluidos en los presupuestos de la República con base en el Plan Nacional de Desarrollo vigente.

El estudio llevado a cabo comprendió la estructura programática-presupuestaria de algunas de las dependencias ministeriales del Poder Ejecutivo a las cuales se les aprobó el Presupuesto Ordinario y Extraordinario mediante Ley de la República, durante los periodos 2007-2010 y 2011-2012, exceptuando al Poder Judicial y al Tribunal Supremo de 
Elecciones, en razón de la autonomía constitucional de la que gozan ambos órganos. Salvo esas excepciones, el resto de dependencias públicas a las que se les dota de recursos presupuestarios también deberían verse reflejadas en acciones y metas específicas en el Plan Nacional de Desarrollo (PND) de los periodos referidos, denominados "Jorge Manuel Dengo Obregón" y "María Teresa Obregón Zamora", respectivamente. A la fecha, las carteras ministeriales suman dieciocho, pero el abordaje investigativo comprende a la mitad de ellas, o sea, $50 \%$ de la población ministerial.

\section{Ministerio del Ambiente y Energía (MINAE)}

Al observar los datos presupuestarios ligados a las acciones estratégicas de las carteras ministeriales sujetas de análisis, surgen una serie de consideraciones al respecto, que ponen en duda la verdadera vinculación que logran las instituciones públicas entre ambos. Por ejemplo, a pesar de que varias de las acciones son idénticas y se alargan por 8 años, ello no genera mayor detrimento al desarrollo nacional, sino que más bien lo fortalecen en tanto se da continuidad a varias de ellas a las que podríamos catalogar de estratégicas para un proyecto país; otras, por el contrario, no se tiene claro si a pesar de su similitud son prácticamente las mismas o solo reminiscencias de las apuntadas en el primer PND 2007-2010. El detalle está en la redacción de la Acción Estratégica per se, así como sus elementos derivados: objetivos, metas e indicadores.

Consideramos que, tal y como señala lo prescrito por Meoño Segura (1986, 2005, 2008, 2011a, 2011b y 2012), la actividad ${ }^{6}$ de cada ente público dictamina las acciones administrativas $y$ operativas que deben llevar a cabo en pro del desarrollo nacional, no debiendo limitarse a un solo mandato constitucional; entonces, la planificación presupuestaria nacional debe

$6 \quad$ El término 'actividad', específicamente en lo tocante a un ente público, ha sido desarrollado profusamente por el autor Johnny Meoño Segura, por lo que referimos al lector a la obra de este titulada Guía para un excelente Gobierno y... para un ciudadano menos indolente, en su capítulo 3. ser más explícita y articulada, manteniendo los elementos planificadores indicados y solo variando lo tocante al aspecto numérico de las metas, pero en esencia todo lo demás debe mantenerse incólume, verbigracia: si dentro de los deberes y responsabilidades del MINAE a partir de su Actividad se encuentra el generar acciones que fortalezcan el patrimonio ambiental del país, estas deben mantenerse sin distingo del periodo presidencial en el que nos encontremos, ya que hablamos de un proyecto país, que es de largo plazo, y que supera por mucho el lapso de 4 años.

A pesar de lo anterior, se extrae de los datos recopilados, que únicamente para el presupuesto 2007 se incluyeron recursos por $\$ 1.000 .000 .000,00$ al Programa 887 CONSERVACIÓN Y MANEJO DE LA DIVERSIDAD, específicamente en la subpartida 5.03.01 TERRENOS; esto para la adquisición de terrenos que pasarían a formar parte del patrimonio ecológico del país. Y es que en el proyecto de Ley de Presupuesto Ordinario y Extraordinario de la República 2007 se incluyó como objetivo de mejora para el programa referido lo siguiente: "Adquisición de tierras para consolidar el patrimonio natural del Estado en las ASP."

Para el Ejercicio Económico 2008, el Programa 887 desaparece $y$ los puestos que pertenecían a él pasan a formar parte del Sistema Nacional de Áreas de Conservación (SINAC) como un órgano desconcentrado del MINAE. No obstante, en los proyectos de Ley para el 2009 y 2010 se incluyó el siguiente objetivo estratégico para el Programa 879 ACTIVIDADES CENTRALES: Fortalecer el patrimonio natural del Estado mediante la adquisición de tierras dentro de las Áreas Silvestres Protegidas (ASP).

Dicho panorama se ensombrece cuando al cierre de la formulación presupuestaria de esos mismos años, el MINAE no había remitido a la Dirección General de Presupuesto Nacional (DGPN) el dictamen de vinculación entre su previsión presupuestaria y el PND, el cual es emitido por el Ministerio de Planificación Nacional y Política Económica; esto según la exposición de motivos presentada por el Ministerio de Hacienda a la Comisión Permanente de Asuntos Hacendarios. 
Entonces, se extrae que una actividad estratégica para Costa Rica en materia de potenciamiento del resguardo ambiental, tal $y$ como la señalada previamente, ha sido operacionalizada de forma esporádica, ya que en lo consecutivo no existen datos que respalden el hecho de que el SINAC haya logrado aumentar el patrimonio ambiental del país.

Considerando lo anterior, resulta innecesario presentar un detalle adicional que ejemplifique los datos numéricos señalados.

\section{Ministerio de Seguridad Pública (MSP)}

Otro ente ministerial como el Ministerio de Seguridad Pública (MSP), también se alejó por mucho de las estimaciones presupuestarias logradas en los PND analizados, específicamente para el cumplimiento de las acciones que lograran una mayor presencia policial a través del aumento en la cantidad de policías. Tales estimaciones para el total del periodo sumaban $\$ 73.796 .500 .000,00$, $y$ entre el año 2007-2012, los recursos incluidos en los proyectos presupuestarios ascendían a $\$ 432.534 .189 .000,00$. No obstante, existe una dificultad para determinar la capacidad real de los mismos, puesto que no existen datos actualizados ni accesibles administrados por la DGPN; esto podemos considerarlo a la luz de la partida presupuestaria mediante la cual se debería lograr el cumplimiento de la meta, siendo esta la 0 denominada 'Remuneraciones'.

Ahora bien, en este caso sí se observa cierta congruencia en cuanto a la estructura programática de los proyectos presupuestarios, propiamente en la exposición de motivos que el Ministerio de Hacienda prepara para el Poder Legislativo, ya que en todos los años se hace referencia a la contratación de nuevos policías. A pesar de ello, el resto de la estructura, o sea, los elementos que deben ser generados por el propio ministerio tal $y$ como indicadores de resultado y de gestión, o los objetivos de mejora, no hacen referencia alguna al nivel de cumplimiento de la meta.

Por ende, el MSP igualmente incurre en un comportamiento intermitente en materia de planificación presupuestaria, comportamiento que se agrava cuando la Contraloría General de la República llamó la atención al analizar el
Proyecto de Presupuesto Ordinario y Extraordinario de la República 2011, señalando los resultados del informe $\mathrm{N}^{\circ}$ DFOE-PGAA-IF-19-2010, mediante el cual se destaca que el MSP no cuenta con estudios que justifiquen la cantidad necesaria de policías para mejorar los índices de seguridad ciudadana (2010, p.37).

A pesar de todo, la cuadrol muestra cómo a contrapelo de lo puntualizado por la Contraloría, el Ministerio de Seguridad Pública ha logrado ensanchar sus recursos presupuestarios de manera sostenida en el tiempo.

\section{CUADRO 1}

RECURSOS ASIGNADOS AL MSP EN

PRESUPUESTOS DE LA REPÚBLICA, PARA LA

PARTIDA 0 (REMUNERACIONES) 2007-2012

\begin{tabular}{cc}
\hline $\begin{array}{c}\text { PERIODO } \\
\text { PRESUPUESTARIO }\end{array}$ & MONTO ASIGNADO \\
\hline 2007 & $45.588 .979 .000,00$ \\
2008 & $49.734 .987 .000,00$ \\
2009 & $63.975 .747 .000,00$ \\
2010 & $81.645 .636 .000,00$ \\
2011 & $92.317 .514 .000,00$ \\
2012 & $99.271 .326 .000,00$ \\
\hline
\end{tabular}

Fuente: Elaboración propia con base en los Proyectos de Presupuesto Ordinario y Extraordinario de la República 2007-2012, para la Partida Presupuestaria 0 (Remuneraciones)

\section{Ministerio de Salud}

En igual sentido hay que referirse a lo relativo a los CEN-CINAI por parte del Ministerio de Salud (MS), en tanto que según los PND valorados, en ambos se incluyen acciones de fortalecimiento a la infraestructura de tales centros. Para el periodo 2007-2014, la previsión presupuestaria fue de $\$ 23.601 .600 .000,00$, pero la real inclusión de recursos para ello la ubicamos en el año 2007 con un monto de $\$ 2.000 .000,00$ en la subpartida 5.02.99 denominada: "Otras construcciones, adiciones y mejoras", y asignado al Programa Presupuestario 622 "DIRECCIÓN Y CONDUCCIÓN EN SALUD". 
En esa misma línea, según la exposición de motivos del proyecto de Ley 2012: "se presupuesta al MOPT en el programa de Edificaciones Nacionales la suma de $\$ 400,0$ millones, para la construcción, ampliación y reparación de CEN-CINAI distribuidos en cantones pertenecientes a las provincias de Heredia, Cartago, Alajuela, Guanacaste, Puntarenas y Limón.” (2011, p.21). Tal argumentación genera dudas sobre la capacidad del MS para concretar una adecuada planificación presupuestaria para una acción que se desprende del propio PND; más aún, también resulta necesario rescatar el hecho de que la DGPN dé como válida la inclusión de esos recursos en un programa presupuestario que no tiene ninguna relación con el Ministerio de Salud que, al final, resulta ser el responsable por lograr el efectivo cumplimiento de las metas e indicadores establecidos.

Considerando lo anterior, resulta innecesario presentar un detalle adicional que ejemplifique los datos numéricos señalados.

\section{Ministerio de Vivienda y Asentamientos Humanos (MIVAH)}

En cuanto al Ministerio de Vivienda y Asentamientos Humanos (MIVAH), este administra recursos con fuentes legales muy específicas y así explicitadas en los proyectos de presupuesto, específicamente en las "Coletillas" presupuestarias, las cuales: "son leyendas que se añaden a los diversos renglones de gasto con el propósito de desglosar montos, destinos, identidad de beneficiarios y otras informaciones relativas a la erogación que se ha de realizar" (CGR, 2006, p.37).

En este caso en particular, el Programa Presupuestario 814 ACTIVIDADES CENTRALES, dispuso de recursos en la subpartida 7.01.06 "Transferencias de capital a instituciones públicas financieras", recursos que fueron segmentados en varias oportunidades según se muestra en la siguiente cuadro. Sin embargo, dichos recursos también sufrieron de intermitencia, pues en algunos años fueron presupuestados $y$ en otros no.

CUADRO 2

DETALLE DE ARGUMENTOS PARA TRANSFERENCIAS DEL MIVAH 2007-2012

\begin{tabular}{ll}
\hline Subpatida presupuestaria & Fundamento de la coletilla presupuestaria \\
\hline $\begin{array}{l}7.01 .06 \text { (200) Transferencias de capital a } \\
\text { instituciones públicas financieras. }\end{array}$ & $\begin{array}{l}\text { Para el periodo 2008-2010: Fondo de Desarrollo Social y Asignaciones } \\
\text { Familiares (FODESAF). (Para transferir al Banco Hipotecario de la } \\
\text { Vivienda (BANHVI), para la asignación de bono colectivo en obras de } \\
\text { infraestructura en asentamientos de precarios, programa de erradicación } \\
\text { de tugurios según artículo } 65 \text { de la Constitución Política y la ley } 7052 \\
\text { o Ley del Sistema Financiero Nacional para la Vivienda y creación del } \\
\text { BANHVI, del 13/11/86 y sus reformas) }\end{array}$ \\
& $\begin{array}{l}\text { Para el año 2011, esta coletilla cambia y se indica Banco Hipotecario de } \\
\text { la Vivienda (BANHVI). (Para financiar programas públicos dirigidos a }\end{array}$ \\
& $\begin{array}{l}\text { la dotación de vivienda digna, según Ley 8683 del 19/11/2008, Ley del } \\
\text { Impuesto Solidario para el Fortalecimiento de Programas de Vivienda). }\end{array}$ \\
$\begin{array}{ll}\text { 7.01.06 (204) Transferencias de capital a a } \\
\text { instituciones públicas financieras. }\end{array}$ & $\begin{array}{l}\text { Instituto Nacional de Vivienda y Urbanismo (INVU). (Para compra de } \\
\text { terrenos para dotar de vivienda a familias en condición de pobreza } \\
\text { extrema en el cantón de Alajuelita, según artículo 65 de la Constitución } \\
\text { Política y Ley 1788. }\end{array}$ \\
$\begin{array}{ll}\text { 7.01.06 (216) Transferencias de capital a a } \\
\text { instituciones públicas financieras. }\end{array}$ & $\begin{array}{l}\text { Banco Hipotecario de la Vivienda (BANHVI). (Para la asignación de bono } \\
\text { colectivo en obras de infraestructura en asentamientos en precario, } \\
\text { programa erradicación de tugurios, según artículo 65 de la Constitución } \\
\text { Política y la Ley 7052, Ley del Sistema Financiero Nacional para la } \\
\text { Vivienda y creación del BANHVI, del 13/11/86 y sus reformas). }\end{array}$ \\
\hline
\end{tabular}

Fuente: Elaboración propia con base en los Proyectos de Presupuesto Ordinario y Extraordinario de la República 2007-2012. 
Se extrae de los PND analizados que, para el MIVAH, se plasmaron acciones estratégicas relacionadas con la generación de soluciones de vivienda, haciendo énfasis en la ayuda a familias en extrema pobreza (asentamientos precarios $y$ tugurios), lo cual se busca materializar a través de los recursos del Fondo de Subsidio para la Vivienda (FOSUVI) o del Programa de Bono Colectivo.

La estimación presupuestaria indicada en el PND 2007-2010 fue de $\$ 92.462 .800 .000,00$ $y$ para el siguiente fue de $\$ 302.128 .920 .000,00$; no obstante, los recursos incluidos en las diferentes partidas presupuestarias destinadas a transferencias explicitadas en la tabla anterior, apenas ascienden a $\$ 56.767 .000 .000,00$ en el periodo 2007-2012. Dicho monto constituye apenas un $14 \%$ de los recursos estimados en los planes analizados, lo cual resulta lógico al valorar el detalle de recursos presupuestarios destinados a las transferencias de referencia.

La intermitencia en el destino de fondos en el Presupuesto de la República para el MIVAH, mismos que según se indica en las coletillas presupuestarias, tienen como base la propia Constitución Política y las diferentes leyes que facultan al Gobierno costarricense para llevar a cabo programas de erradicación de viviendas en precario y tugurio, refleja una desatención plausible al esquema de planificación presupuestaria, desatención que por la naturaleza de las acciones necesarias de llevar a cabo impacta sensible y negativamente en el desarrollo nacional, y obviamente en las condiciones de la población de escasos recursos.

La desvinculación entre la planificación presupuestaria y el PND para el caso del MIVAH, debe de alguna manera achacársele igualmente al Ministerio de Hacienda, considerando por ejemplo lo indicado por este último a la Asamblea Legislativa en el Proyecto de Presupuesto 2007:

Dentro de los programas prioritarios que este Ministerio ha definido para la actual Administración, se pueden señalar principalmente los dirigidos al fomento de una vivienda digna para los costarricenses; erradicación de precarios y tugurios, tanto en zonas rurales como en el área metropolitana, y el mejoramiento de las condiciones de vida de los barrios marginales o en situación de pobreza. (MH, 2006c, p.22)

Por lo tanto, no se encuentra asidero para la no inclusión de recursos presupuestarios que vengan a solventar la serie de necesidades poblacionales, tal y como el de vivienda digna. Lo anterior se magnifica, cuando también la Contraloría General de la República (2008, 2009a, 2009c), cuestionó la inclusión intermitente de recursos para estos fines, así como el evidente riesgo del no cumplimiento de las metas establecidas para el PND 2007-2010, riesgo que reiteró el órgano contralor para el PND 2011-2014 (2011).

El siguiente cuadro permite observar lo hasta aquí indicado para dicha cartera ministerial.

CUADRO 3

RECURSOS ASIGNADOS AL MIVAH

EN PRESUPUESTOS DE LA REPÚBLICA, DISTRIBUIDOS POR COLETILLA PARA LA SUBPARTIDA 7.01.06 2007-2012

\begin{tabular}{cc}
\hline $\begin{array}{c}\text { COLETILLA } \\
\text { PRESUPUESTARIA }\end{array}$ & MONTO ASIGNADO \\
\hline 200 & $31.242 .000 .000,00$ \\
204 & $1.000 .000 .000,00$ \\
216 & $22.175 .000 .000,00$ \\
\hline
\end{tabular}

Fuente: Elaboración propia con base en los Proyectos de Presupuesto Ordinario y Extraordinario de la República 2007-2012, para la Subpartida Presupuestaria 7.01.06.

\section{Ministerio de Agricultura y Ganadería (MAG)}

Para el caso del MAG se plasmaron acciones sumamente similares entre los PND aquí analizados $y$ destinadas al acompañamiento $y$ asistencia brindada a productores nacionales a través de asistencia técnica y transferencia tecnológica. 
Para el PND 2007-2010 se buscó apoyar a 61960 productores, generando una estimación presupuestaría para ello de $\$ 500$ millones de colones, y para el PND 2011-2014 la cantidad de unidades productoras que se buscan apoyar es de 1720 , siendo la respectiva estimación presupuestaria de $\$ 1.840 .000 .000,00$.

Según pudo extraerse de los proyectos de presupuesto del periodo analizado, los rubros que más se acercaban a lograr el cumplimiento de las metas establecidas se ubicaron en la subpartida 7.03.02 "Transferencias de capital a fundaciones"; esto se indica en razón de lo plasmado en la coletilla que acompaña a esa subpartida. Bajo ese prisma, sería la transferencia a la Fundación para el Fomento y Promoción de la Investigación y Transferencia de Tecnología Agropecuaria en Costa Rica -FITTACORI-, la que como se indica, se acerca más al cumplimiento de la meta.

La coletilla presupuestaria indicada señala para todos los años lo siguiente: (convenio MAG-FITTACORI). (Para la ejecución de proyectos de investigación y transferencia de tecnología agropecuaria para el pequeño y mediano productor costarricense).

Valga indicar que la dificultad por determinar si los recursos apuntados vienen a lograr el cumplimiento de las metas establecidas, radica en la no especificación por parte del ente responsable de los recursos y la propia DGPN, sobre los montos presupuestarios destinado a esas acciones, aunado a la no incorporación permanente en la estructura programática presupuestaria de términos referenciales que brinden claridad al respecto. Por lo que únicamente para los proyectos de presupuesto 2011 y 2012 se incluyeron objetivos estratégicos institucionales que consideramos se vinculan al cumplimiento del PND.

En esa misma línea, la Contraloría General ha sido reiterativa (2008, 2009c, 2010, 2011 y 2012b) en que existe una debilidad en la estructura programática presupuestaria, ya que esta "sigue sin mostrar expresamente la vinculación de los programas y partidas de los diferentes títulos presupuestarios al Plan Nacional de Desarrollo" (2009, p.7)

Precisamente en el Informe para el presupuesto 2012, indicó el ente contralor la siguiente observación, la cual es factible de generalizar para el resto de proyectos presupuestarios:

(...) se concluye que el proyecto de presupuesto 2012, carece de los elementos necesarios para poder contar con una base suficiente y completa para medir la efectividad de los programas, el costo unitario de los servicios y la eficiencia en el uso de los recursos. Esta situación ha venido siendo advertida por la Contraloría en años anteriores con ocasión de la emisión de su Informe Técnico de Presupuesto ante el trámite del proyecto de presupuesto en esa Asamblea Legislativa, $y$ tales carencias en la formulación, han conllevado a que al final del período, el MINHAC no haya cumplido finalmente con lo dispuesto en el artículo 52 de la LAFRPP, respecto de brindar los elementos explicativos que debe contener el informe de evaluación, limitándose seriamente el proceso de rendición de cuentas. Ante tal situación, la Asamblea Legislativa debe prestar la mayor atención en el trámite de discusión y aprobación del proyecto de presupuesto. (CGR, 2012b, p.81)

De igual manera, el cuadro 4 permite denotar que los recursos presupuestarios asignados al MAG en el periodo 2007-2012 han sido incrementales, muy a pesar de la imposibilidad manifiesta para determinar si los mismos se dirigen fielmente al cumplimiento del PND y a la actividad de ese ministerio. 
CUADRO 4

RECURSOS ASIGNADOS AL MAG EN

PRESUPUESTOS DE LA REPÚBLICA, PARA LA

SUBPARTIDA 7.03.02

2007-2012

\begin{tabular}{lr}
\hline PERIODO & MONTO ASIGNADO \\
PRESUPUESTARIO & $22.000 .000,00$ \\
2007 & $40.000 .000,00$ \\
2008 & $50.000 .000,00$ \\
2009 & $40.000 .000,00$ \\
2010 & $60.000 .000,00$ \\
2011 & $162.400 .000,00$ \\
2012 & \\
\hline
\end{tabular}

Fuente: Elaboración propia con base en los Proyectos de Presupuesto Ordinario y Extraordinario de la República 2007-2012, para la Subpartida Presupuestaria 7.03.02.

\section{Ministerio de Educación Pública (MEP)}

No consideramos que las acciones que se enmarquen en un proyecto de envergadura nacional/global como los anteriores, se traslapen de un Plan Nacional de Desarrollo al siguiente sin que aparezcan resultados tangibles, $y$ peor aún, sin que se logre el cumplimiento efectivo de los recursos presupuestarios destinados para ello. Prueba de lo anterior es lo apuntado por el Ministerio de Educación Pública (MEP) para el proyecto MEP-Digital.

Para ese proyecto se tuvo una proyección presupuestaria según el PND 2007-2010 de $\$ 352.200 .000,00$ y para el PND 2011-2014 de $\$ 2.294 .000 .000,00$; no obstante, el total de recursos detectados en los proyectos de presupuesto del periodo 2007-2012 ascienden a $\$ 4.055 .851 .000,00$, superando en $\$ 1.726 .631 .000,00$ dichas estimaciones presupuestarias. El escenario se complica cuando del total de recursos económicos presupuestados para el lapso referido, únicamente se logra detectar la ejecución de $\$ 666.798 .488,00$, o sea, un $16 \%$, lo cual permite evidenciar una holgura entre las acciones consideradas estratégicas por el MEP y su capacidad de planificación presupuestaria y de ejecución real de los recursos, lo cual obviamente permite inferir que otras actividades de ese ministerio dirigidas a la población estudiantil están siendo desatendidas por canalizar recursos a proyectos que no terminan de concretarse.

Valga rescatar que en la estructura programática-presupuestaria del MEP para los proyectos de presupuesto 2007-2012 se incluyeron de manera intermitente enunciados sobre MEP-Digital, por ejemplo, en el 2007 como un objetivo de mejora para el Programa Presupuestario 572 ADMINISTRACIÓN DEL SISTEMA EDUCATIVO, para los años 2009 y 2010 como objetivo estratégico del Programa Presupuestario 555 APLICACIÓN DE LA TECNOLOGÍA A LA EDUCACIÓN. Para el resto del periodo estudiado no se localizaron argumentos claros al respecto; no obstante, lo extraído permite considerar que existe una falta de coherencia en el esquema de planificación presupuestaria del MEP, al no mantener una misma línea de cumplimiento para tal esquema; en otras palabras, se genera una estimación presupuestaria en el PND que se aleja por mucho de los recursos incluidos en los diferentes ejercicios económicos.

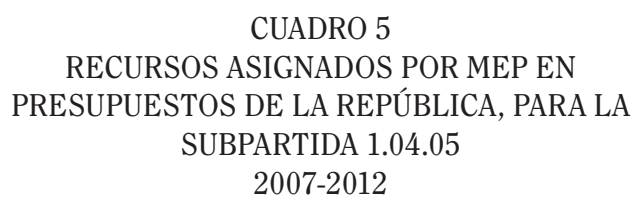

\begin{tabular}{lr}
\hline PERIODO & MONTO ASIGNADO \\
PRESUPUESTARIO & $1.228 .000 .000,00$ \\
\hline 2007 & $800.000 .000,00$ \\
2008 & $25.000 .000,00$ \\
2009 & $331.551 .000,00$ \\
2010 & $943.550 .000,00$ \\
2011 & $727.750 .000,00$ \\
2012 & \\
\hline
\end{tabular}

Fuente: Elaboración propia con base en los Proyectos de Presupuesto Ordinario y Extraordinario de la República 2007-2012, para la Subpartida Presupuestaria 1.04.05.

\section{Ministerio de Trabajo y Seguridad Social (MTSS)}

En el caso del Ministerio de Trabajo y Seguridad Social (MTSS), se ha incluido una 
acción estratégica destinada a la constitución de un mecanismo de identificación y control para el uso de los recursos del Fondo de Desarrollo Social y Asignaciones Familiares (FODESAF). La estimación presupuestaria para el PND 2007-2010 fue de $\$ 48$ millones y para el periodo 2011-2014 de $\$ 200$ millones.

Resulta imprescindible indicar que analizados los proyectos presupuestarios de esa cartera ministerial, no se localizaron recursos dirigidos al cumplimiento de dicha acción, más aún, la meta para el cumplimiento de la misma en el segundo periodo analizado, o sea 2011-2014, le corresponde al Instituto Mixto de Ayuda Social (IMAS) y a la Caja Costarricense del Seguro Social (CCSS), lo que a todas luces resulta incongruente con las responsabilidades del MTSS, siendo esta entidad la única responsable de desarrollar el Sistema de Indicadores que mejor le resulte para controlar el uso que se le da a los recursos que llegan al fondo.

La incongruencia apuntada se acentúa cuando los mismos proyectos presupuestarios reflejan en su estructura programática para los años 2007, 2008, 2009 y 2011, objetivos de mejora institucional, prioridades institucionales y objetivos estratégicos relativos a concretar la generación del instrumento administrativo mencionado. En el mismo sentido, huelga referirse a lo prescrito en la exposición de motivos generada por el Ministerio de Hacienda para el Proyecto de Ley de Presupuesto 2009, indicando que según oficio DM-307-08 del jerarca de MIDEPLAN, se realizó un diagnóstico de vinculación que determinó que la Matriz Anual de Programación Institucional (MAPI) presenta consistencia con el Plan Nacional de Desarrollo y continúa:
Algunas de las Acciones Estratégicas relacionadas a los objetivos estratégicos podemos mencionar: - Desarrollo y aplicación de un Sistema de Indicadores para el Control y Evaluación del uso de los recursos del Fondo de Desarrollo Social y Asignaciones Familiares (FODESAF). (MH, 2008a, p.112)

Nótese cómo una acción administrativa considerada como plenamente vinculante con el PND, no ha sido sujeta de inyección de recursos por el ente responsable, lo que obliga a referirse a la existencia de un incumplimiento en materia de planificación presupuestaria por parte del MTSS, que incluso ha sido observada por los órganos responsables de coordinar esta última (DGPN y MIDEPLAN), sin que se hayan generado mayores acciones correctivas.

\section{Ministerio de Obras Públicas y Transportes-Consejo Nacional de Vialidad}

Especial atención merecen los rubros presupuestarios reflejados al MOPT, específicamente las transferencias al Consejo Nacional de Vialidad (CONAVI), en razón de los argumentos vertidos en el apartado antecedental.

Las acciones estratégicas que vinculan al CONAVI con el desarrollo nacional, e implícitamente con la planificación presupuestaria, atañen por supuesto a la infraestructura vial nacional (caminos o puentes), sea a nivel de construcción, rehabilitación-reconstrucción y mejoramiento.

La siguiente tabla presenta el detalle de las transferencias presupuestarias a favor de ese ente de desconcentración máxima. 


\section{CUADRO 6 \\ DETALLE DE ARGUMENTOS PARA TRANSFERENCIAS DEL MOPT AL CONAVI 2007-2012}

\begin{tabular}{|c|c|}
\hline Subpartida presupuestaria & Fundamento de la coletilla presupuestaria \\
\hline $\begin{array}{l}\text { 6.01.02 Transferencias corrientes a órganos } \\
\text { desconcentrados. }\end{array}$ & $\begin{array}{l}\text { Para atender lo dispuesto en la Ley } 8114 \text { de } 4 / 7 / 2001 \text {, art.5, inciso a). } \\
\text { a) El setenta y cinco por ciento ( } 75 \%) \text {, se destinará exclusivamente } \\
\text { a la conservación, el mantenimiento rutinario, el mantenimiento } \\
\text { periódico, el mejoramiento y la rehabilitación; una vez cumplidos } \\
\text { estos objetivos, los sobrantes se emplearán para construir obras } \\
\text { viales nuevas de la red vial nacional. }\end{array}$ \\
\hline $\begin{array}{l}\text { 7.01.02 (201) Transferencias de capital a órganos } \\
\text { desconcentrados. }\end{array}$ & $\begin{array}{l}\text { Para atender lo dispuesto en la Ley } 7798 \text { de } 29 / 5 / 98 \text {, art. } 20 \text {, inciso b) } \\
\text { ARTíCULO 20.- Créase el Fondo para la atención de la red vial } \\
\text { nacional, que estará constituido por los siguientes tributos, ingresos } \\
\text { y bienes: } \\
\text { b) El monto equivalente al cincuenta por ciento ( } 50 \%) \text { de los } \\
\text { ingresos recaudados por el impuesto a la propiedad de vehículos, } \\
\text { previsto en el artículo } 9 \text { de la Ley } 7088 \text {. Esta disposición será } \\
\text { reglamentada en conjunto por el Ministerio de Hacienda y el } \\
\text { Ministerio de Obras Públicas y Transportes. }\end{array}$ \\
\hline $\begin{array}{l}\text { 7.01.06 (203) Transferencias de capital a órganos } \\
\text { desconcentrados. }\end{array}$ & $\begin{array}{l}\text { Consejo Nacional de Vialidad - CONAVI - (Para atender lo dispuesto } \\
\text { en la Ley } 8114 \text { de } 4 / 7 / 2001 \text {, art.5, inciso a), incluye los recursos del } \\
3 \% \text { signados al laboratorio de materiales y modelos estructurales } \\
\text { de la Universidad de Costa Rica (LANAMME). Los recursos } \\
\text { correspondientes al LANAMME serán utilizados exclusivamente } \\
\text { en la fiscalización de los proyectos en ejecución o en proceso de } \\
\text { contratación) }\end{array}$ \\
\hline
\end{tabular}

Fuente: Elaboración propia con base en los Proyectos de Presupuesto Ordinario y Extraordinario de la República 2007-2012 y en el SINALEVI de la Procuraduría General de la República.

Puede valorarse que los argumentos plasmados para las transferencias arriba indicadas tienen una base legal muy clara, lo que significa que los impuestos establecidos mediante las leyes 7798 y 8114 no son transitorios, $y$ por lo tanto, este aspecto conlleva a que el CONAVI logre una planificación presupuestaria que trasciende por mucho el periodo de 4 años, lo que permite arribar al hecho de que los proyectos de ese ente para con el desarrollo nacional a través del mejoramiento de la infraestructura vial del país, son a largo plazo, sin demeritar aquellos que por su naturaleza surjan de forma imprevista o de corto plazo.

Indicado lo anterior, se tiene una base firme para considerar que los proyectos del CONAVI deberían ser sencillos de identificar, incluso a nivel de la estructura programática, esto dada la naturaleza ya apuntada ( y continua) de dichos proyectos.

No obstante, en el PND 2007-2010 y su homólogo de 2011-2014, no se visualizan proyectos específicos que vengan a sustentar lo aquí indicado; por ende, la inyección de recursos 
en los diferentes proyectos presupuestarios no encuentra amalgama con el respectivo PND. Los indicadores anexos a las transferencias arrojan como dato global que estas ascienden en el periodo 2007-2012 a $\$ 616.749 .800 .000,00$; no obstante, se carece de información con un nivel de especificidad aceptable a nivel de PND y la consiguiente estructura programática presupuestaria ligada a él, capaz de orientar sobre los destinos que tendrían los recursos ahí plasmados.

Según pudo valorarse en la exposición de motivos que envía el Ministerio de Hacienda a la Comisión Permanente de Asuntos Hacendarios para cada Proyecto de Ley de Presupuesto de la República, únicamente para el proyecto del 2012 se presenta un breve detalle de los proyectos por desarrollar por parte del MOPT-CONAVI en materia de mejoramiento de la infraestructura vial (MH, 2011, p.25). Por el contrario, la estructura programática presupuestaria del MOPT para la mayoría de años se ha restringido a la presentación de indicadores de resultado y de gestión, los cuales son solamente enunciados numéricos que refieren a kilómetros de la red vial nacional atendidos, o a metros de puentes atendidos. Ciertamente, esos enunciados poco orientan sobre la efectividad en la formulación de un presupuesto que resulta vital para el desarrollo nacional, en razón de lo que representa la infraestructura vial para cualquier país en la actualidad, sea en materia de desplazamiento de mercancías y comercio en general, turismo, etc.; en otras palabras, hablamos de mecanismos para fortalecer la competitividad país.

Estos vacíos han sido señalados por la Contraloría General de forma hasta cierto punto continua, a pesar de haber vertido argumentos relativos al MOPT-CONAVI en varios de los Informes Técnicos sobre los proyectos presupuestarios, sus señalamientos no se considera que sean puntuales sobre la no vinculación entre el PND y la consiguiente planificación presupuestaria. Aun así, es rescatable lo indicado por el ente fiscalizador en el 2008:

Del análisis realizado se desprende que no hay una vinculación integral del POI del $M O P T$ con el PND, consecuentemente, no se declaran las razones por las cuales los recursos presupuestarios necesarios para las acciones estratégicas del PND no contempladas en el POI no se consideran en el Proyecto de Presupuesto Ordinario del MOPT para el 2009. (p.101)

En consecuencia, la CGR se queda corta en cuanto a la desvinculación entre el PND y la planificación presupuestaria en el caso del MOPT-CONAVI, máxime cuando esa instancia ha sido blanco de críticas precisas por parte de muchos sectores, sobre todo de los medios de comunicación.

A continuación, se tabula el total de recursos girados a esta instancia durante el periodo analizado.

\section{CUADRO 7}

RECURSOS ASIGNADOS AL MOPT-CONAVI

EN PRESUPUESTOS DE LA REPÚBLICA, DISTRIBUIDOS POR SUBPARTIDA DE TRANSFERENCIA 2007-2012

\begin{tabular}{ll}
\hline PARTIDA & MONTO ASIGNADO \\
PRESUPUESTARIA & \\
\hline 6.01 .02 & $24.500 .000,00$ \\
$7.01 .02(201)$ & $209.490 .000 .000,00$ \\
$7.01 .02(203)$ & $382.759 .800 .000,00$ \\
\hline
\end{tabular}

Fuente: Elaboración propia con base en los Proyectos de Presupuesto Ordinario y Extraordinario de la República 2007-2012, para las Subpartidas Presupuestarias de Transferencias.

\section{Otras consideraciones diagnósticas}

El anterior análisis versó sobre la aparente vinculación entre los recursos presupuestarios solicitados por los diferentes entes ministeriales y el efectivo logro de las Acciones Estratégicas incluidas en el respectivo PND.

No obstante, otra consideración a la que pudo arribarse, es que existe toda una gama de recursos presupuestarios, principalmente ubicados a nivel de transferencias, los cuales no encuentran parámetro en razón de los PND 
considerados. Muchos de ellos se relacionan con organismos nacionales e internacionales que es muy seguro que coadyuven con el logro del desarrollo nacional. No obstante, no se encuentran asomos de ese trabajo conjunto entre el ente ministerial $y$ el respectivo organismo receptor de los recursos, lo que obliga a argüir que cualquier recurso presupuestario que se encuentre en esa condición no abona al mejor desarrollo nacional.

En esa línea la disparidad entre los recursos con aparente base en la planificación pre- supuestaria $y$ sin ella asciende a un total de $\$ 736.323 .355 .247,00$.

Se ha señalado previamente, que el Plan Nacional de Desarrollo es el instrumento articulador, dinamizador, contralor y evaluador por excelencia para el desarrollo nacional. Pero no puede considerarse el documento único sobre el cual descansa la planificación nacional, incluso a nivel global. Según el criterio analítico empleado, el esquema de planificación presupuestaria pública en Costa Rica lo ubicamos de la siguiente manera: 


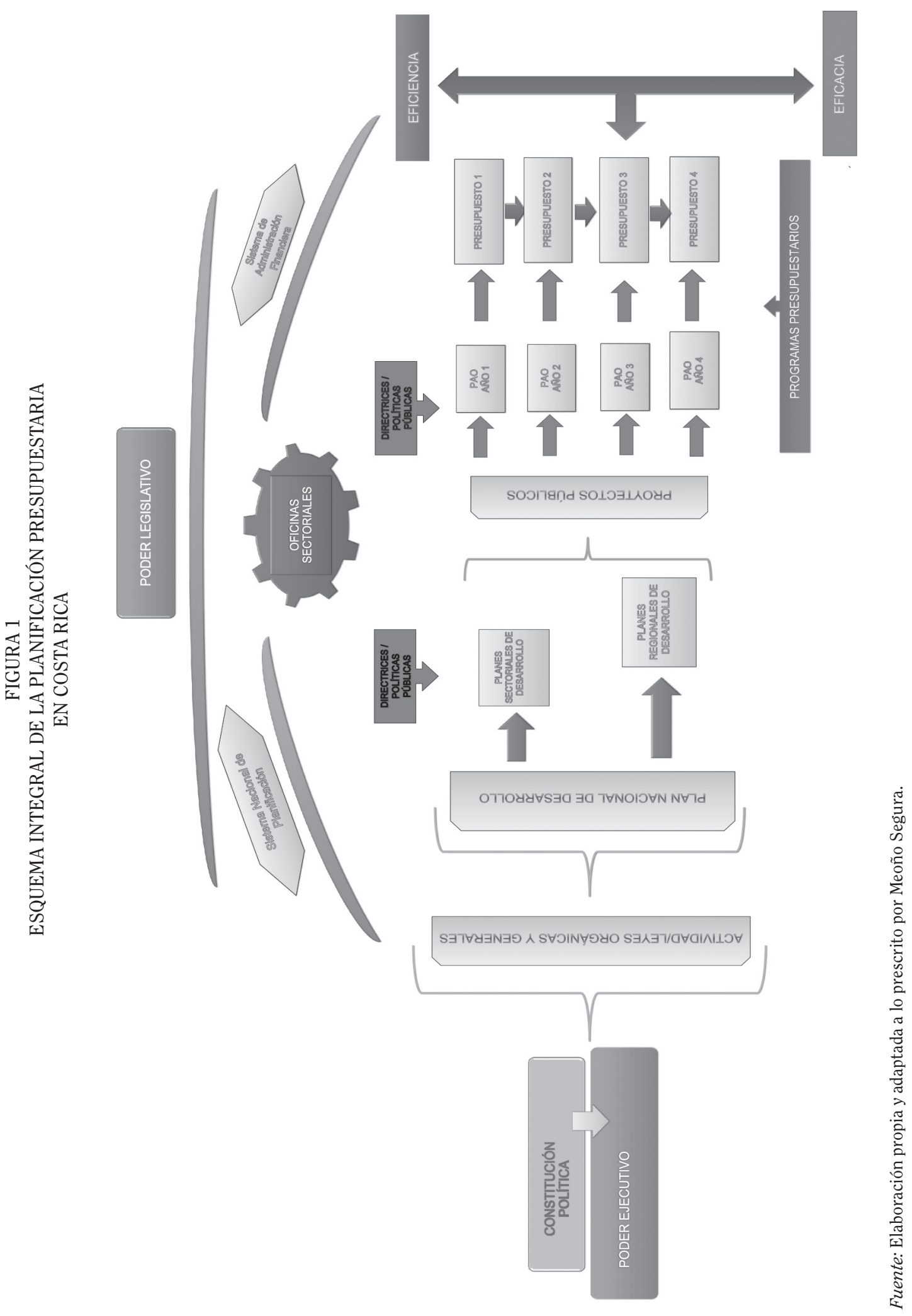


Según se denota en ese esquema, el PND debe ser ese gran marco orientador, direccionador, movilizador y evaluador para el desarrollo nacional, el cual consta de niveles de desagregación: Planes Regionales de Desarrollo, Planes Sectoriales de Desarrollo y Planes Anuales Operativos, los cuales hemos denominado como apéndices de segundo, tercer y cuarto grado, respectivamente.

Hacemos eco de la tesis de Meoño (2012, p.40-45), al prescribir que del PND deben desprenderse luego, en forma concreta y detallada, las formulaciones sobre política regional y sectorial, hasta llegar a las de cada institución pública.

Esto no podría ser de otra manera, e incluso se le debe agregar otro apéndice a la estructura esquemática en fiel apego a lo prescrito por Albert Waterson (1969) y al ILPES (1980), al presentar los proyectos como el último eslabón de la planificación presupuestaria, los cuales serán posibles siempre y cuando se haya logrado generar correctamente la identificación de las necesidades poblacionales en las regionales del país.

Entonces, recapitulando, el esquema de planificación presupuestaria debe iniciar con la formulación del PND, el cual en términos generales y no específicos, aglutina consideraciones de orden regional y sectorial; posteriormente, se generan los planes regionales, los sectoriales, los planes anuales operativos, $y$ a partir de este último apéndice se formula el presupuesto de cada institución pública, el cual deberá inexorablemente dirigirse al cumplimiento efectivo de los proyectos que buscan atender de manera muy particular $y$ directa a todos los anteriores.

Por lo tanto, la estructura programática de cada presupuesto público debe ser fiel reflejo del último nivel de desagregación, o sea, los proyectos, ya que de lo contrario se incurre en la generación de indicadores de todo tipo (objetivos de mejora, prioridades institucionales, de resultado y de gestión, etc.), que no terminan de aterrizar en las metas que debe lograr el Sistema de Administración Pública para el desarrollo nacional, sin importar el campo de acción del que se trate: educación, seguridad ciudadana, vivienda, desarrollo agroalimentario, etc.
Como vigilantes y garantes de esa vinculación que debería ser irrompible, están los encargados del Sistema Nacional de Planificación (MIDEPLAN) y del Sistema de Administración Financiera (Ministerio de Hacienda), apoyándose concomitantemente, $y$ apoyando al Presidente de la República a lograr instrumentar esa política gubernativa de desarrollo activada a partir del PND.

Precisamente, en el diagnóstico generado están ausentes muchos de los elementos articuladores indicados y plasmados en el esquema de la figura 1, razón suficiente para comprender el porqué de las intermitencias, disparidades, aumentos $y$ disminuciones de recursos en los proyectos de presupuesto aquí analizados, sin obviar las mismas falencias en lo tocante a las argumentaciones que sustentan tales proyectos, comentadas previamente.

Como resultado, es imposible determinar con total certeza la cantidad de recursos que los programas presupuestarios ministeriales asignan al PND, sea en términos totales y porcentuales, aspecto ya indicado por el ente contralor, según se especificara al analizar lo tocante a los proyectos presupuestarios del MAG.

\section{CONCLUSIONES}

Para lograr tener un panorama claro sobre la vinculación entre los presupuestos públicos y el Plan Nacional de Desarrollo, se procedió a analizar la serie de datos cuantitativos y cualitativos alrededor de los proyectos de Ley de Presupuesto Ordinario y Extraordinario de la República para el periodo 2007-2012, específicamente para los siguientes entes ministeriales: Ministerio de Seguridad Pública, Ministerio de Educación Pública, Ministerio de Salud, Ministerio de Ambiente y Energía, Ministerio de Vivienda y Asentamientos Humanos, Ministerio de Agricultura y Ganadería, y finalmente, el Ministerio de Trabajo y Seguridad Social.

Se buscó determinar a partir de los datos presupuestarios, los niveles totales y porcentuales de los recursos incluidos en los presupuestos de la República y que tuvieran como base irrestricta el respectivo Plan Nacional de Desarrollo. 
Para ello, se extrajeron los datos específicos para cada ente ministerial, pero no solo a nivel presupuestario, sino también a nivel de la estructura programática del Plan Nacional de Desarrollo 2007-2010: "Jorge Manuel Dengo Obregón” y del siguiente 2011-2014: "María Teresa Obregón Zamora".

Se pudo denotar que existen elementos programáticos como: acciones estratégicas, objetivos $y$ metas que prácticamente se continúan entre un plan y el otro; esto a primera vista no sería algo negativo si se estuviera cumpliendo con la actividad del ente, lo cual significa atender las funciones $y$ responsabilidades poblaciones por las cuales este nace a la vida jurídica y administrativa nacional, encomendándosele la prestación de un determinado servicio público; la cual da margen para que tales elementos programáticos perduren a lo largo de los años, siendo que se atienden necesidades poblacionales $y$ oportunidades para el desarrollo que no acaban en un periodo tan corto, $y$ por lo tanto, los presupuestos de los ministerios automáticamente se vuelven plurianuales.

No obstante, en algunos casos, por ejemplo del MEP y del Ministerio de Trabajo y Seguridad Social, la continuidad de sus acciones estratégicas son seriamente cuestionables, en razón de que no parecen acabar a lo largo de un periodo constitucional de 4 años, con la desazón de que el primero excedió por mucho las previsiones presupuestarias plasmadas en el primer PND 2007-2010, y el segundo ni siquiera incluyó alguna cifra presupuestaria para el cumplimiento de su meta durante todo el periodo analizado.

En los casos del MINAE, Ministerio de Salud y el MIVAH, la intermitencia en la inclusión de recursos presupuestarios para cumplir con sus obligaciones para con el desarrollo nacional, ha sido la norma y no la excepción. El primero y segundo únicamente incluyeron recursos durante un ejercicio económico, mientras que el MIVAH si bien tuvo mayor constancia en la inclusión de recursos en los diferentes presupuestos sujetos de análisis, no logró cumplir con la estimación presupuestaria prevista, alcanzando, según los datos recopilados, apenas un $14 \%$ de la misma.
Lo tocante al Ministerio de Seguridad Pública resulta trascendental, ya que ha logrado un sostenimiento incremental de sus recursos presupuestarios destinados a cumplir con las acciones estratégicas propias de los respectivos Planes de Desarrollo. A pesar de ello, dos consideraciones son dignas de rescatar:

a) Existe una dificultad manifiesta por determinar el verdadero monto destinado a lograr el cumplimiento de la meta, infiriéndose que se trata de la subpartida 0 , denominada "Remuneraciones".

b) Según aclaró la Contraloría General de la República, ese Ministerio no cuenta con estudios que determinen la cantidad necesaria de efectivos policiales que mejoren los niveles de seguridad ciudadana en el territorio nacional, por lo cual los incrementos presupuestales deben a toda luz considerarse superfluos.

Los casos del Ministerio de Agricultura y Ganadería, y del MOPT-CONAVI son similares al del MSP, al presentar una debilidad idéntica a nivel en su estructura programático-presupuestaria. Y es que según pudo demostrarse gráficamente, los recursos presupuestarios asignados a ambos en el periodo 2007-2012 han sido incrementales, muy a pesar de la imposibilidad manifiesta para determinar si los mismos se dirigen fielmente al cumplimiento del PND. Por lo tanto, tales incrementos deben considerarse igualmente superfluos en razón del desarrollo nacional.

Llegados a este punto, resulta imprescindible reiterar lo señalado por la Contraloría General de la República, en el sentido de que los proyectos de Ley de Presupuesto Ordinario y Extraordinario de la República para el periodo 2007-2012 carecen de los elementos necesarios para poder contar con una base suficiente y completa para medir la efectividad de los programas, el costo unitario de los servicios $y$ la eficiencia en el uso de los recursos; igualmente, se sigue sin mostrar expresamente la vinculación de los programas y partidas de los diferentes títulos presupuestarios al PND. Todo esto apunta a la imposibilidad de determinar 
cuántos y cuáles de los recursos presupuestarios aquí analizados han finalmente podido aportar al mejor desarrollo nacional.

Con base en lo anterior, resulta absolutamente imposible determinar los niveles totales $y$ porcentuales de recursos presupuestarios que destinan actualmente los entes ministeriales costarricenses hacia el cumplimiento del Plan Nacional de Desarrollo.

Una conclusión neurálgica que consideramos se yuxtapone a todo lo anterior, es que no se tiene claro el esquema planificador del desarrollo costarricense, el cual permite presentar los proyectos públicos como el último eslabón de la planificación presupuestaria, y hacia el cual apunten todos los recursos públicos, sobre todo los presupuestarios.

La técnica de Presupuesto por Programas o también denominada Programa Presupuestario, resulta ser un planteamiento que abarcó a toda América Latina a partir de los planteamientos de la Comisión Económica para América Latina de las Naciones Unidas (CEPAL), particularmente de su funcionario Gonzalo Martner.

Los programas presupuestarios consideramos son el último eslabón del esquema planificador nacional, $y$ por ende, los responsables finales por lograr no solo la formulación/ generación de proyectos públicos, sino también la adecuada formulación de los presupuestos públicos que permitirán en definitiva la concreción de los primeros, correlativamente logrando la concreción exitosa de los mecanismos de estratégicos de dirección gubernativa: planes sectoriales, regionales y el propio PND.

Entonces, conforme los datos cuantitativos $y$ cualitativos presentados, $y$ el consiguiente análisis de los mismos, así como de toda otra información atinente, se logra demostrar que el gasto público no está correctamente dirigido al logro del desarrollo nacional, situación que a todas luces se traducirá tarde o temprano en un aumento del déficit fiscal, no habiendo vinculación entre la planificación presupuestaria y el Plan Nacional de Desarrollo del momento, lo cual ha sido señalado reiteradamente por el ente contralor nacional, sin que se hayan tomado medidas correctivas incluso a nivel del Poder Legislativo.

De esa desvinculación ubicamos como responsables al Ministro de Planificación Nacional como responsable máximo del Sistema Nacional de Planificación, y al Ministro de Hacienda como responsable máximo del Sistema de Administración Financiera, sin restarle responsabilidades a la Contraloría General de la República como ente fiscalizador de la Hacienda Pública, así como a las Comisiones Legislativas de Asuntos Hacendarios, y de Control de Ingreso y Gasto Público, las cuales han podido poner coto a esta situación, exigiendo un adecuado ejercicio de la dirección gubernativa, para articular el desempeño presupuestario y administrativo de las instituciones públicas en función del PND y sus apéndices.

No obstante, las anteriores comisiones presentan una debilidad adicional señalada por el BID y el Banco Mundial, la cual debería fenecer a través del ejercicio de las prescripciones aquí planteadas. Y es que señalan esos organismos que: "[sus] análisis presupuestarios no se respaldan en Guías técnicas sino en el conocimiento y experiencia de los Miembros del CAH y del Subcomité de presupuesto" (BID/BM, 2010, p.137).

La LAFRPP es la norma que finalmente termina de aclarar la actuación de las instituciones públicas en razón del desarrollo nacional dictado por el Presidente de la República por medio del ligamen Plan-Presupuesto. Esa aclaración se da al generar toda una serie de valoraciones propias que, junto con las prescritas previamente por Johnny Meoño Segura, nos hacen concebir cómo los presupuestos públicos son los tipos de medios para concretar las metas o proyectos públicos que permiten finalmente la concreción exitosa del PND.

Pero, todo lo anterior pasa por reconocer al PND como ese gran marco orientador, direccionador, movilizador y evaluador para el desarrollo nacional, el cual consta de niveles de desagregación: Planes Regionales de Desarrollo, Planes Sectoriales de Desarrollo y Planes Anuales Operativos, los cuales denominamos como apéndices de segundo, tercer y cuarto grado, respectivamente. 
Por lo tanto, debe, finalmente, reconocerse que el esquema planificador del desarrollo es la conjunción de una serie de actores propios del Sistema de Administración Pública, así como también de una serie de conceptos $y$ acciones propias de la dirección y planificación gubernativas, lo que en otras palabras conlleva a cavilar sobre la correcta forma de poner en práctica esas dos primeras fases del proceso administrativo. Deben entonces reconsiderarse conceptos poco o nada conocidos, $y$ peor aún, inexistentes en la praxis de la planificación presupuestaria, verbigracia: dirección gubernativa, planificación nacional, Plan Nacional de Desarrollo, directrices, metas, tipos de medios, presupuestos públicos, entre otros; todo esto, con el claro objetivo de enmarcar y orientar los recursos de las instituciones públicas hacia un desarrollo nacional articulado y tangible, coherente en razón de las necesidades poblacionales.

La figura 1 permite visualizar de mejor forma la interacción de los elementos sistémicos mencionados. Ese esquema no se perfila recubierto de consideraciones filosóficas o falaces, sino que aglutina e incorpora todos aquellos elementos sistémicos que deben brindar funcionalidad a la planificación presupuestaria costarricense, sin incurrir en el trasplante de esquemas o fórmulas foráneas carentes de armonía para con el contexto jurídico-administrativo nacional.

\section{REFERENCIAS}

Asamblea Legislativa de la República de Costa Rica. Ley de Administración Financiera de la República y Presupuestos Públicos 8131. En Diario Oficial La Gaceta 198 de 16 de octubre de 2001.

Asamblea Legislativa de la República de Costa Rica (1995). Ley de contratación administrativa 7494. Recuperado de http://www.pgrweb.go.cr/scij/Busqueda/ Normativa/Normas/nrm_texto_completo. aspx?param1=NRTC\&nValor1=1\&nValor2 $=24284 \&$ nValor $3=97014 \&$ strTipM $=$ TC

Asamblea Legislativa de la República de Costa Rica. (1978). Ley general de la Administración Pública 6227.
Recuperado de http://www.pgrweb.go.cr/ scij/Busqueda/Normativa/Normas/nrm texto_completo.aspx?param1=NRTC\&nV alor1=1\&nValor2=13231\&nValor3=90116 \&strTipM=TC

Asamblea Legislativa de la República de Costa Rica (1984). Ley para el equilibrio financiero del sector público 6955. Recuperado de http://www.pgrweb.go.cr/ scij/Busqueda/Normativa/Normas/nrm_ texto_completo.aspx?param1=NRTC\&nV alor1 $=1 \&$ nValor $2=6199 \&$ nValor $3=80883$ \&param2 $=1 \&$ strTipM=TC\&1Resultado $=2$ $\&$ strSim $=$ simp

Asamblea Legislativa de la República de Costa Rica. (1974). Ley de Planificación Nacional 5525. Recuperado de http://www.pgrweb.go.cr/scij/Busqueda/ Normativa/Normas/nrm_texto_ completo.aspx?param1=NRTC\&nValor1= $1 \&$ nValor2=34439\&nValor3=91172\&para $\mathrm{m} 2=1 \&$ strTipM=TC\&1Resultado $=3 \& s t r S i$ $\mathrm{m}=\operatorname{simp}$

Banco Interamericano de Desarrollo (BID)/ Banco Mundial (BM). (2010). Costa Rica: Informe de Desempeño de la Gestión de las Finanzas Pública (PEFA). Recuperado de www.pefa.org/en/assessment/files/227/ $\mathrm{rpt} / 382$

Bolaños, R. (2014). Planificación presupuestaria en la Administración Pública costarricense: su implicancia en el desarrollo nacional. (Tesis Doctoral inédita). UNED, San José.

Bolaños, R. (enero-junio, 2012). Breve historicidad y encuadre técnicojurídico para el ejercicio de la dirección gubernativa. Revista de Ciencias Económicas 30 (1), 435-447.

Comisión Económica para América Latina y el Caribe (CEPAL)/Secretaría General Iberoamericana (SEGIB). (2011). Espacios Iberoamericanos. Hacia una nueva arquitectura del Estado para el desarrollo. Santiago: CEPAL.

Contraloría General de la República. (2012a). Normas Técnicas sobre Presupuesto Público N-1-2012-DC-DFOE. San José: CGR. 
Contraloría General de la República. (2012b). Informe Técnico al Proyecto de Ley de Presupuesto de la República 2012. San José: CGR.

Contraloría General de la República. (2012c). Presupuestos públicos 2012. Situación y perspectivas. San José: CGR.

Contraloría General de la República. (2012d). Memoria Anual 2011. San José: CGR.

Contraloría General de la República. (2011). Informe Técnico al Proyecto de Ley de Presupuesto de la República 2012. San José: CGR.

Contraloría General de la República. (2010). Informe Técnico al Proyecto de Ley de Presupuesto de la República 2011. San José: CGR.

Contraloría General de la República. (2009a). Nota-Informe No. DFOE-SAFIF-11-2009, referente a "Estudio sobre mejoras al proceso de formulación del Plan Nacional de Desarrollo 2010-2014". San José: CGR.

Contraloría General de la República. (2009b). Lineamientos Generales sobre la Planificación del Desarrollo Local. San José: CGR.

Contraloría General de la República. (2009c). Informe Técnico al Proyecto de Ley de Presupuesto de la República 2010. San José: CGR.

Contraloría General de la República. (2008). Informe Técnico al Proyecto de Ley de Presupuesto de la República 2009. San José: CGR.

Contraloría General de la República. (2007a). Informe DFOE-SAF-21-2007 Estudio sobre el Sistema Nacional de Planificación. San José: CGR.

Contraloría General de la República. (2007b). Informe Técnico al Proyecto de Ley de Presupuesto de la República 2008. San José: CGR.

Contraloría General de la República. (2006). Informe Técnico al Proyecto de Ley de Presupuesto de la República 2007. San José: CGR.

Fayol, H. (1957). Administración Industrial y General. Buenos Aires: El Ateneo.
Instituto Latinoamericano y del Caribe de Planificación Económica y Social (ILPES). (1980). Discusiones sobre planificación.-11 edición.- México: Siglo Veintiuno.

Martner, G. (1989). Planificación y Presupuestos por programas.-17 edición.México: Siglo Veintiuno.

Meoño, J. (2012). Análisis de los procesos de dirección, planificación gubernativa, políticas públicas y reforma del Estado en Costa Rica. Revista de Ciencias Económicas, 30 (1), 13-72.

Meoño, J. (2011a). Planificación del Desarrollo. Lecciones de la experiencia. San José: Instituto de Investigaciones en Ciencias Económicas, Universidad de Costa Rica.

Meoño, J. (2011b). Fiscalización de la Hacienda Pública: ¿Cuán efectiva en Costa Rica? San José: Escuela de Ciencias Políticas-Facultad de Ciencias Sociales, Universidad de Costa Rica.

Meoño, J. (2008). Guía para un excelente Gobierno... y para un ciudadano menos indolente. San José: Instituto de Investigaciones en Ciencias Económicas, Universidad de Costa Rica.

Meoño, J. (2005). Exigencia y rendición de cuentas sobre ingreso y gasto público: un análisis de lo que jurídica, institucional $y$ politicamente puede hacerse en la materia. San José: Instituto de Investigaciones en Ciencias Económicas, Universidad de Costa Rica.

Meoño, J. (1986). Administración Pública: Teoría y Práctica.-2 edición.- San José: EUCR.

Ministerio de Hacienda. (2011). Presentación de Proyecto de Ley de Presupuesto Ordinario y Extraordinario de la República, para el Ejercicio Económico 2012. Recuperado de http://www. hacienda.go.cr/contenido/432-leyes-depresupuestos-2012

Ministerio de Hacienda. (2010). Presentación de Proyecto de Ley de Presupuesto Ordinario y Extraordinario de la República, para el Ejercicio Económico 2011. Recuperado de http://www. 
hacienda.go.cr/contenido/444-leyes-depresupuestos-2011

Ministerio de Hacienda. (2009). Presentación de Proyecto de Ley de Presupuesto Ordinario y Extraordinario de la República, para el Ejercicio Económico 2010. Recuperado de http://www. hacienda.go.cr/contenido/446-leyes-depresupuestos-2010

Ministerio de Hacienda. (2008). Presentación de Proyecto de Ley de Presupuesto Ordinario y Extraordinario de la República, para el Ejercicio Económico 2009. Recuperado de http://www.hacienda.go.cr/contenido/448leyes-de-presupuestos-2009

Ministerio de Hacienda. (2007). Presentación de Proyecto de Ley de Presupuesto Ordinario y Extraordinario de la República, para el Ejercicio Económico 2008. Recuperado de http://www. hacienda.go.cr/contenido/451-leyes-depresupuestos- 2008

Ministerio de Hacienda. (2006). Presentación de Proyecto de Ley de Presupuesto Ordinario y Extraordinario de la República, para el Ejercicio Económico 2007. Recuperado de http://www. hacienda.go.cr/contenido/470-leyes-depresupuestos-2007
Sala Constitucional del Poder Judicial. (2002). Resolución 2002-12019. Recuperado de http://www.pgrweb.go.cr/scij/Busqueda/ Normativa/asunto_cons/asu_asunto_ const.aspx?param1=ASC\&nValor1=1\&pa ram5=96-002914-0007-CO\&strTipM=E

Sala Constitucional del Poder Judicial. (1997). Resolución 6345-97. Recuperado de http://www.pgrweb.go.cr/scij/Busqueda/ Normativa/asunto_cons/asu_asunto_ const.aspx?param1=ASC\&nValorl=1\&pa ram5=94-004830-0007-CO\&strTipM=E

Tavares, M. y Berreta, N. (2006). Sistemas de Planificación Estratégica e Innovaciones Presupuestarias. Recuperado de http://www.cepal.org/ilpes/noticias/ paginas/2/36342/Planificacion_ Estrategica_y_Presupuesto.pdf

Tinbergen, J. (1959). La planeación del desarrollo. México: Fondo de Cultura Económica.

Vidal, H. (Editor). (1979). Presupuesto por Programas: Conceptos, Metodologías y Estrategias. San José: EDUCA/ICAP.

Waterson, A. (1969). Planificación del Desarrollo. Lecciones de la experiencia. México: Fondo de Cultura Económica. 
